\title{
National Institute on Deafness and Other Communication Disorders
}

National Cancer Institute

\section{Source}

National Cancer Institute. National Institute on Deafness and Other Communication

Disorders. NCI Thesaurus. Code C82608.

An institute within the National Institutes of Health that is mandated to conduct and support biomedical and behavioral research and research training in the normal and disordered processes of hearing, balance, smell, taste, voice, speech, and language. 